\title{
Influence of Degree of Compaction on Unsaturated Hydraulic Properties of a Compacted Completely Decomposed Granite
}

\author{
Rui Chen $\mathbb{D}^{1},{ }^{1}$ Runqiang Tan, ${ }^{1}$ Zhongkui Chen $\mathbb{D}^{1},{ }^{1}$ Yang Ping $\mathbb{D},{ }^{2}$ and Zhen Mei ${ }^{1}$ \\ ${ }^{1}$ School of Civil and Environmental Engineering, Harbin Institute of Technology, Shenzhen 518055, China \\ ${ }^{2}$ Shenzhen Water Planning and Design Institute Co., Ltd., Shenzhen 518000, China \\ Correspondence should be addressed to Yang Ping; pingy@swpdi.com
}

Received 13 October 2019; Accepted 9 January 2020; Published 29 January 2020

Academic Editor: Maurizio Barbieri

Copyright ( 2020 Rui Chen et al. This is an open access article distributed under the Creative Commons Attribution License, which permits unrestricted use, distribution, and reproduction in any medium, provided the original work is properly cited.

\begin{abstract}
It is crucial to understand hydraulic properties, i.e., soil-water characteristic curve (SWCC) and unsaturated permeability function (UPF), of completely decomposed granite (CDG) for relevant engineering projects in southeastern China. Previous studies mainly focused on SWCCs of CDG, whereas UPFs of CDG have not yet been well understood. In this study, the effects of the degree of compaction (DOC) on SWCCs and UPFs of CDG were investigated based on experiments where suction range was from 0 to $500 \mathrm{kPa}$. The microstructure of soil specimens was then analyzed by mercury intrusion porosimetry (MIP). Furthermore, the UPFs of CDG under different values of DOC were calculated using four prediction models and compared with experimental data. Results showed that the pore volume of specimens at higher DOC was smaller than that at lower DOC, and there were more macropores observed in specimens at lower DOC. Meanwhile, it was found that increasing compaction effort produced negligible influence on the volume of micropores. When the suction was less than $100 \mathrm{kPa}$, the permeability was reduced with the increase in DOC, due to the decrease of macropore volume. However, the influence of DOC on SWCCs and UPFs became marginal when the suction exceeded $100 \mathrm{kPa}$. The Fredlund and Xing model provided the best prediction of UPF among the four models when suction was smaller than air entry value (AEV). It is suggested that these models could be improved to capture UPFs at higher suctions than AEV by considering suction-induced volume contraction.
\end{abstract}

\section{Introduction}

In the southeastern coastal area of China, completely decomposed granite (CDG) with thicknesses up to $50 \mathrm{~m}$ is widely distributed on the gentle hills and terraces. Evaporation causes the reduction of soil water content, resulting in the change of hydraulic properties, i.e., soil-water characteristic curve (SWCC) and unsaturated permeability function (UPF) $[1,2]$, particularly of CDG in the tropical and subtropical areas such as southeastern China. Previous studies mainly focused on SWCCs of CDG, whereas UPFs of CDG have not yet been well understood since there are only limited relevant experimental studies.

Hydraulic properties of CDG have received much attention. Tang et al. [3] used the osmotic method to obtain drying and wetting SWCCs of CDG. They found that both desorption and absorption rates of SWCC were relatively small and the air entry value (AEV) was only about $10 \mathrm{kPa}$. Chen and Gong [4] studied the effect of initial dry density on SWCCs of CDG using the filter paper method and concluded that increasing initial dry density caused an increase in the $\mathrm{AEV}$ but a decrease in the desorption rate. Yin [5] measured the saturated permeability coefficients of CDG under different degrees of compaction (DOC) by fallinghead permeability tests and found that with the increase in DOC, the saturated permeability coefficient decreased linearly in a semilogarithmic coordinate system.

However, investigations related to the unsaturated permeability experiments were limited. One of the foremost reasons may be that the direct measurement of UPF is a time-consuming task, and it also needs specific test equipment [6]. In order to address the above problems, Schindler and Müller [7] proposed a simplified evaporation method, which only requires a short test period $(2 \sim 3 \mathrm{~d})$ and simple equipment but produces relatively accurate results simultaneously for SWCC and UPF using one soil 
specimen [7, 8]. However, most existing evaporation methods are only applicable within a limited suction range due to the capacity of conventional tensiometers (i.e., suction from 0 to $90 \mathrm{kPa}$ ), which results in a limited range of measured SWCC and UPF.

Many mathematical prediction models have also been proposed to obtain the UPFs of soils. The typical models include the Fredlund and Xing model [9], the van Genuchten model [10], the Brooks and Corey model [11], and the Gardner model [12]. The SWCC and saturated permeability coefficient are the prerequisites of determining the UPF in these four models. Gallage et al. [6] measured the hydraulic properties of sand at different dry densities and predicted the UPFs using three of the abovementioned models. It was found that the predictions were consistent with the measured data within a suction range of $0 \sim 10 \mathrm{kPa}$. However, further verifications are needed for a higher suction range. Furthermore, it was found that some prediction methods were not accurate enough for predicting the UPFs of cohesive soils $[9,10]$, and the measurement range of SWCC (i.e., $1000 \mathrm{kPa}, 1500 \mathrm{kPa}$, and $10000 \mathrm{kPa}$ ) affected the predicted UPFs [13].

Since the SWCC and UPF of CDG play key roles in seepage analysis of relevant geotechnical projects, it is crucial to find a method to quickly and accurately measure the hydraulic properties of CDG under a relatively wide suction range $[14,15]$.

The objectives of this study are (1) to measure hydraulic properties, i.e., SWCCs and UPFs, of CDG at different values of DOC within the suction range of $0 \sim 500 \mathrm{kPa}$ using the simplified evaporation method and a high-capacity tensiometer; (2) to understand the effects of DOC on UPFs of CDG by combining microscopic investigations with the results of the simplified evaporation tests; and (3) to examine the applicability of prediction models for the UPFs of CDG.

\section{Material and Methods}

2.1. Experimental Material. The CDG used in this study was taken from a construction site in Shenzhen, China. The tests for physical properties of soil were carried out in accordance with the Standard Soil Test Methods in China [16]. The summary of the basic properties of CDG is shown in Table 1, whereas the particle-size distribution curve of the CDG is shown in Figure 1.

2.2. Specimen Preparation. After taking the soil sample from the site, it was dried in an oven at $50^{\circ} \mathrm{C}$. Subsequently, the dried soil was crushed with a rubber hammer and then passed through a $5 \mathrm{~mm}$ sieve. Water was added and mixed thoroughly with the dried soil to the optimum water content of $19 \%$. Thereafter, the well-mixed wet soil was kept inside a zipped plastic bag for moisture equilibrium lasting about $24 \mathrm{~h}$ in a humidity- and temperature-controlled room [17]. Static compaction was used to form soil specimens $(62 \mathrm{~mm}$ in diameter and $95 \mathrm{~mm}$ in height) at the desired DOC of $80 \%$, $90 \%$, and $95 \%$, respectively. The soil was compacted in five layers in a cylindrical compaction mold with each sublayer of $19 \mathrm{~mm}$ thickness. The interface between two layers was scarified to achieve uniformity. To ensure the repeatability
TABle 1: Physical properties of test material.

\begin{tabular}{lc}
\hline Physical property & Value \\
\hline Gravel (\%) & 42.0 \\
Sand (\%) & 27.7 \\
Silt (\%) & 17.1 \\
Clay (\%) & 13.2 \\
Particle size (effective) at which 10\% of & 0.002 \\
soil particles are finer, $D_{10}(\mathrm{~mm})$ & \\
Particle size at which $30 \%$ of soil particles & 0.025 \\
are finer, $D_{30}(\mathrm{~mm})$ & \\
Particle size at which $60 \%$ of soil particles & 0.793 \\
are finer, $D_{60}(\mathrm{~mm})$ & 0.394 \\
Coefficient of curvature, $C_{\mathrm{c}}$ & 396.5 \\
Coefficient of uniformity, $C_{\mathrm{u}}$ & 24.1 \\
Plastic limit, $\omega_{\mathrm{p}}(\%)$ & 36.3 \\
Liquid limit, $\omega_{\mathrm{L}}(\%)$ & 12.2 \\
Plasticity index, $I_{\mathrm{P}}=\omega_{\mathrm{L}}-\omega_{\mathrm{p}}$ & 2.602 \\
Specific gravity, $G_{\mathrm{s}}$ & 19.0 \\
Optimum water content, $\omega_{\mathrm{opt}}(\%)$ & 1.66 \\
Maximum dry density, $\rho_{\mathrm{d}, \mathrm{Max}}\left(\mathrm{g} / \mathrm{cm}^{3}\right)$ & \\
\hline
\end{tabular}

of the experimental results, 6 replicates were prepared for each DOC. For each DOC, 3 replicates were utilized to perform the simplified evaporation tests, and the saturated permeability coefficient was measured using the rest of the replicates, after being placed in a vacuum cylinder for saturation.

2.3. Measurement of Saturated Permeability Coefficient. Saturated permeability coefficients of CDG at different values of DOC were measured in a flexible-wall permeameter according to test standard ASTM-D5084 [18]. After saturation, the soil specimen was installed in a triaxial pressure cell and the saturated permeability coefficient was measured using the falling-head method according to

$$
k_{\mathrm{s}}=\frac{a \times L}{A \times\left(t_{2}-t_{1}\right)} \ln \left(\frac{h_{1}}{h_{2}}\right) \text {, }
$$

where $k_{s}$ denotes the saturated permeability coefficient, $a$ is the inner section area of the burette, $L$ is the height of soil specimen, $t_{1}$ is the time at the beginning of the test, $t_{2}$ is the time at the end of the test, $A$ is the cross-sectional area of the soil specimen, $h_{1}$ is the hydraulic head at $t_{1}$, and $h_{2}$ is the hydraulic head at $t_{2}$.

2.4. Simplified Evaporation Method. In this study, a simplified evaporation method $[7,8,19]$ was utilized for obtaining the hydraulic properties of CDG, i.e., SWCC and UPF during a drying process. The schematic diagram and photo of the test devices are shown in Figure 2. After the soil specimen was saturated, it was taken out together with the plexiglass cylinder. Subsequently, the bottom of the soil specimen was sealed, and two holes were drilled along the height of the soil specimen for installing tensiometers. The presaturated high- 


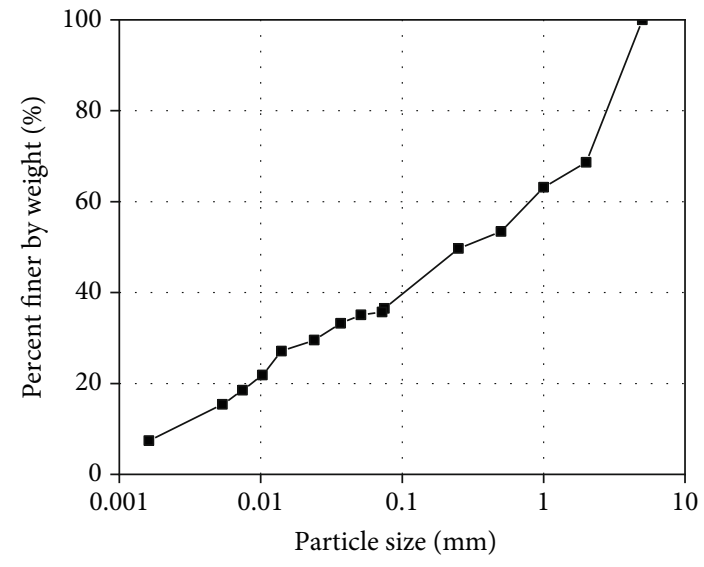

Figure 1: Particle-size distribution of CDG used in this study.

capacity tensiometers [20] were inserted into the two boreholes, and each tensiometer was connected with a power supply and a millivoltmeter. Prior to the test, the tensiometers, cylinder, batteries, and millivoltmeters were placed upon an electronic balance with an accuracy of $0.1 \mathrm{~g}$, and the top surface of the soil specimen was kept exposed to the atmosphere. A camera was set up to record the readings of the millivoltmeters and electronic balance at time intervals of $10 \mathrm{~min}$ [19]. Each point on the measured SWCCs of CDG at different values of DOC was determined as follows: after the simplified evaporation test, the soil specimen was dried in an oven, then the water content of the soil specimen at a certain time was calculated according to the balance readings recorded at that time and the weight of the dried soil specimen; the value of soil suction was equal to the average value of the two tensiometer readings.

The unsaturated permeability coefficient $k(\psi)$ of the middle soil layer is calculated according to the Darcy law [7]:

$$
k(\bar{\psi})=\frac{\Delta V}{2 A \times \Delta t \times i_{\mathrm{m}}},
$$

where $\bar{\psi}$ is the mean suction of the middle soil layer over a given time interval $(\Delta t) ; \Delta V$ is the volume of evaporated soil water from the specimen over $\Delta t$, which is calculated from the mass reduction measured by an electronic balance over $\Delta t$, assuming water density equals $1 \mathrm{~g} / \mathrm{cm}^{3} ; A$ is the crosssectional area of the specimen; and $i_{\mathrm{m}}$ is the mean value of hydraulic gradients in the specimen at the start (i.e., $t_{1}$ ) and at the end (i.e., $t_{2}$ ) of $\Delta t$, given by

$$
i_{\mathrm{m}}=\frac{1}{2}\left(\frac{\psi_{t 1, \mathrm{upper}}-\psi_{t 1, \text { lower }}}{\Delta z}+\frac{\psi_{t 2 \text {,upper }}-\psi_{t 2, \text { lower }}}{\Delta z}\right)-1
$$

where $\psi_{t 1 \text {,upper }}$ and $\psi_{t 1 \text { lower }}$ denote the suction measured by the upper and lower tensiometers at the start time $t_{1}$, respectively; $\psi_{t 2 \text {,upper }}$ and $\psi_{t 2 \text { lower }}$ denote the suction measured by the upper and lower tensiometers at the end time $t_{2}$, respectively; and $\Delta z$ is the vertical distance between the upper and lower tensiometers, in $\mathrm{m}$. For details on the data interpretation, one can refer to Chen et al. [19].
2.5. Determination of AEV. AEV was determined by the following method [21]: by extending the portion of the SWCC with a constant slope and intersecting the suction axis at saturated water content, the corresponding suction value can be obtained, which is called the AEV, $\psi_{b}$.

2.6. Mercury Intrusion Porosimetry (MIP) Test. Soil specimens at DOC of $80 \%$ and $95 \%$ after the completion of the simplified evaporation test were selected for MIP tests to obtain the pore size distribution of the specimens. Two soil clods approximately $15 \mathrm{~mm}$ in diameter were extracted from each soil specimen. To preserve the pore structure and minimize the drying-induced shrinkage of the soil specimen, a freeze-drying method using liquid nitrogen was used [22]. After soil clods were frozen in liquid nitrogen for $15 \mathrm{~min}$, the soil clods were placed in a freeze-drier for at least $48 \mathrm{~h}$. Once the soil clods were prepared, the pore size distribution of the soil specimen was then measured using a MIP (PoreMaster 60GT, Quantachrome Instruments).

2.7. Models for Fitting SWCC and Prediction of UPF. Four models, i.e., Gardner, Brooks and Corey, van Genuchten, and Fredlund and Xing [9-12], were used to fit the SWCCs of soil specimens at different values of DOC. The best fit of different models were determined by obtaining the largest coefficients of determination $\left(R^{2}\right)$. Subsequently, UPFs were also predicted using these four models and compared with the measured data.

2.7.1. Gardner Model. Find the best fit for the SWCC data using

$$
\theta=\theta_{\mathrm{r}}+\frac{\theta_{\mathrm{s}}-\theta_{\mathrm{r}}}{1+a_{1} \psi^{n_{1}}}
$$

where $\theta$ is the volumetric water content, $\theta_{\mathrm{s}}$ is the saturated volumetric water content, $\theta_{\mathrm{r}}$ is the fitting parameter and represents the residual volumetric water content, $\psi$ is the soil suction, and $a_{1}$ and $n_{1}$ are fitting parameters.

After the values of parameters $\theta_{\mathrm{r}}, a_{1}$, and $n_{1}$ were obtained, the UPF was then calculated as follows:

$$
k(\psi)=\frac{k_{\mathrm{s}}}{1+a_{1} \psi^{n_{1}}},
$$

where $k(\psi)$ is the hydraulic permeability of the soil when the suction is $\psi$ and $k_{\mathrm{s}}$ is the saturated permeability coefficient.

2.7.2. Brooks and Corey Model. The best fit for the SWCC data is obtained using Equations (6) and (7), when

$$
\psi<\psi_{b}, \theta=\theta_{s},
$$

and when

$$
\psi \geq \psi_{b}, \theta=\theta_{\mathrm{r}}+\left(\theta_{\mathrm{s}}-\theta_{\mathrm{r}}\right)\left(\frac{\psi_{b}}{\psi}\right)^{\lambda}
$$




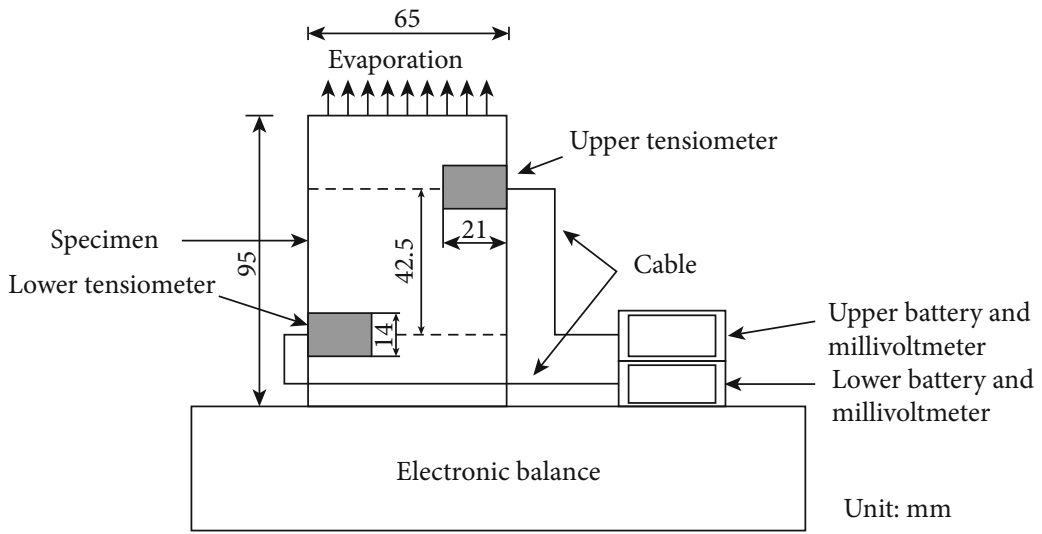

(a) Schematic diagram

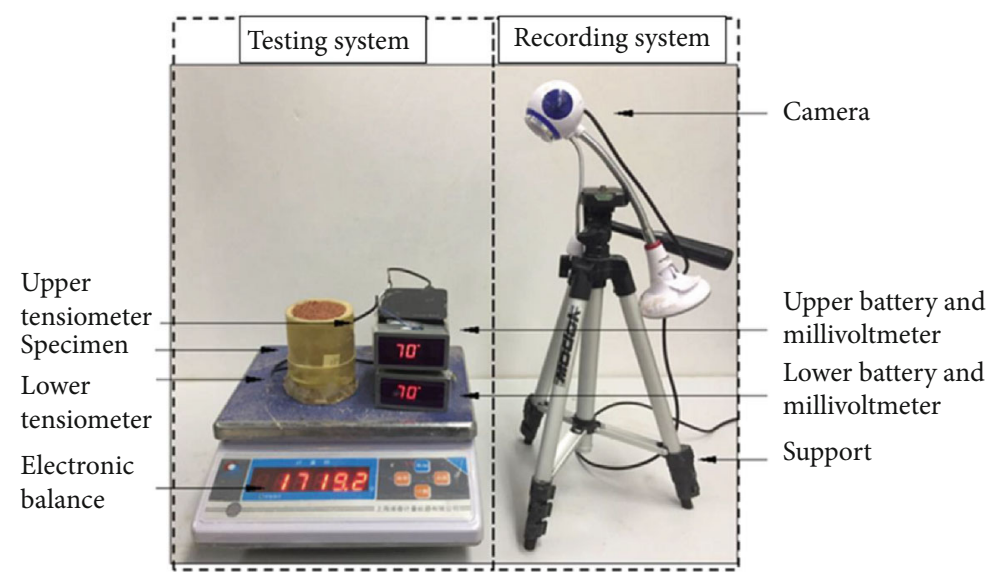

(b) Photo

FIGURE 2: Set-up for measuring unsaturated hydraulic properties based on the simplified evaporation method.

where $\theta$ is the volumetric water content, $\theta_{\mathrm{s}}$ is the saturated volumetric water content, $\theta_{\mathrm{r}}$ is the fitting parameter and represents residual volumetric water content, $\psi$ is the soil suction, $\psi_{b}$ is $\mathrm{AEV}$, and $\lambda$ is the fitting parameter.

Subsequently, UPF was calculated using Equations (8) and (9), when

$$
\psi<\psi_{b}, k=k_{s},
$$

and when

$$
\psi \geq \psi_{b}, k(\psi)=k_{s}\left(\frac{\psi_{b}}{\psi}\right)^{2+3 \lambda},
$$

where $k(\psi)$ is the hydraulic permeability of the soil when the suction is $\psi$ and $k_{\mathrm{s}}$ is the saturated permeability coefficient.

\subsection{3. van Genuchten Model. Fit the SWCC data using}

$$
\theta=\theta_{\mathrm{r}}+\frac{\left(\theta_{\mathrm{s}}-\theta_{\mathrm{r}}\right)}{\left[1+\left(\psi / a_{2}\right)^{n_{2}}\right]^{m_{1}}},
$$

where $\theta$ is the volumetric water content, $\theta_{\mathrm{s}}$ is the saturated volumetric water content, $\theta_{\mathrm{r}}$ is the fitting parameter and represents residual volumetric water content, and $a_{2}$ and $n_{2}$ are fitting parameters, and it is generally assumed that $m_{1}=1-1 / n_{2}$.

Using the parameters $\theta_{\mathrm{r}}, a_{2}, m_{1}$, and $n_{2}$, UPF was calculated using

$$
k(\psi)=k_{\mathrm{s}} \frac{\left\{1-\left(\psi a_{2}\right)^{n_{2} m_{1}}\left[1+\left(\psi a_{2}\right)^{n_{2}}\right]^{-m_{1}}\right\}^{2}}{\left[1+\left(\psi a_{2}\right)^{n_{2}}\right]^{m_{1} / 2}},
$$

where $k(\psi)$ is the hydraulic permeability of the soil when the suction is $\psi$ and $k_{\mathrm{s}}$ is the saturated permeability coefficient.

2.7.4. Fredlund and Xing Model. The SWCC can be expressed using

$$
\theta=\left[1-\frac{\ln \left(1+\left(\psi / \psi_{\mathrm{r}}\right)\right)}{\ln \left(1+\left(10^{6} / \psi_{\mathrm{r}}\right)\right)}\right] \frac{\theta_{\mathrm{s}}}{\left[\ln \left(e+\left(\psi / a_{3}\right)^{n_{3}}\right)\right]^{m_{2}}},
$$

where $\theta$ is the volumetric water content; $\theta_{\mathrm{s}}$ is the saturated volumetric water content; $\psi$ is the soil suction; $\psi_{\mathrm{r}}$ is the curve fitting parameter and represents residual suction; $a_{3}, n_{3}$, and $m_{2}$ are the fitting parameters; and $e$ is the natural constant. 
UPF was calculated using

$$
k(\psi)=k_{\mathrm{s}}\left\{\frac{\int_{\ln (\psi)}^{b}\left(\left(\theta\left(e^{y}\right)-\theta\left(e^{y}\right)\right) / e^{y}\right) \theta^{\prime}\left(e^{y}\right) d y}{\int_{\ln \left(\psi_{b}\right)}^{b}\left(\left(\theta\left(e^{y}\right)-\theta_{\mathrm{s}}\right) / e^{y}\right) \theta^{\prime}\left(e^{y}\right) d y}\right\},
$$

where $\theta^{\prime}$ is the first derivative of Equation (12), $y$ is a dummy variable of integration representing the logarithm of suction, $\psi_{b}$ is the $\mathrm{AEV}, k(\psi)$ is the unsaturated permeability coefficient of the soil when the suction is $\psi$, and $k_{\mathrm{s}}$ is the saturated permeability coefficient.

\section{Results and Discussion}

3.1. SWCCs. Figure 3 shows the measured SWCCs of CDG at different values of DOC. As shown in this figure, both saturated volumetric water content and AEV were significantly affected by DOC. For instance, the AEVs were $17 \mathrm{kPa}$, $30 \mathrm{kPa}$, and $40 \mathrm{kPa}$ for soil specimens at DOC of $80 \%, 90 \%$, and $95 \%$, respectively. Furthermore, increasing DOC slowed down the desorption rate of SWCC in the transition zone. It should be noted that the values of residual water content could not be obtained from the measured SWCCs in this study. Figures 4 and 5 show the MIP results of soil specimens at different values of DOC. The soil specimen at lower DOC had a larger volume of macropores with radii ranging from $0.3 \mu \mathrm{m}$ to $5 \mu \mathrm{m}$ (zone III in Figure 5), whereas the one at higher DOC had a larger volume of micropores with radii ranging from $0.14 \mu \mathrm{m}$ to $0.3 \mu \mathrm{m}$ (zone II in Figure 5). The cumulative pore volume of a soil specimen at DOC of $95 \%$ was $27 \%$ lower than that at DOC of $80 \%$, which means that an increase in DOC led to an increase in soil dry density and hence a decrease in the pore volume. Chen and Gong [4] believed that the increase of the volume of micropores enhanced the soil water retention capacity. In other words, more micropores made it more difficult for air to enter the soil and hence slowed down the desorption rate. Similar findings were reported for silty soil [23], sand [6], and clay [24]. It should be noted that, as shown in Figure 4, the cumulative pore volume curve of a soil specimen at DOC of $80 \%$ had a flat portion at pore radii ranging from $4 \mu \mathrm{m}$ to $10 \mu \mathrm{m}$. This is because in the MIP test, the pore volume within the soil mass was determined by continuously increasing the mercury injection pressure. However, due to the "ink bottle" effect [25], when the injection pressure was not high enough, the mercury could not completely fill the pores with corresponding pore size. In other words, the results of MIP tests were affected by pore nonuniformity [26].

Figures 6-8 show the fitted SWCCs for CDG at different values of DOC, and the fitting parameters are summarized in Table 2. As shown in these figures, all models except the Brooks and Corey model provided good fitting to the measured data within the suction range of $0 \sim 500 \mathrm{kPa}$, and all the coefficients of determination $R^{2}$ of these models exceed 0.92. The Brooks and Corey model showed relatively poor fitting. This is because the Brooks and Corey model is a piecewise function, and it assumes that soil water content is unchanged when suction is less than AEV, thereby leading

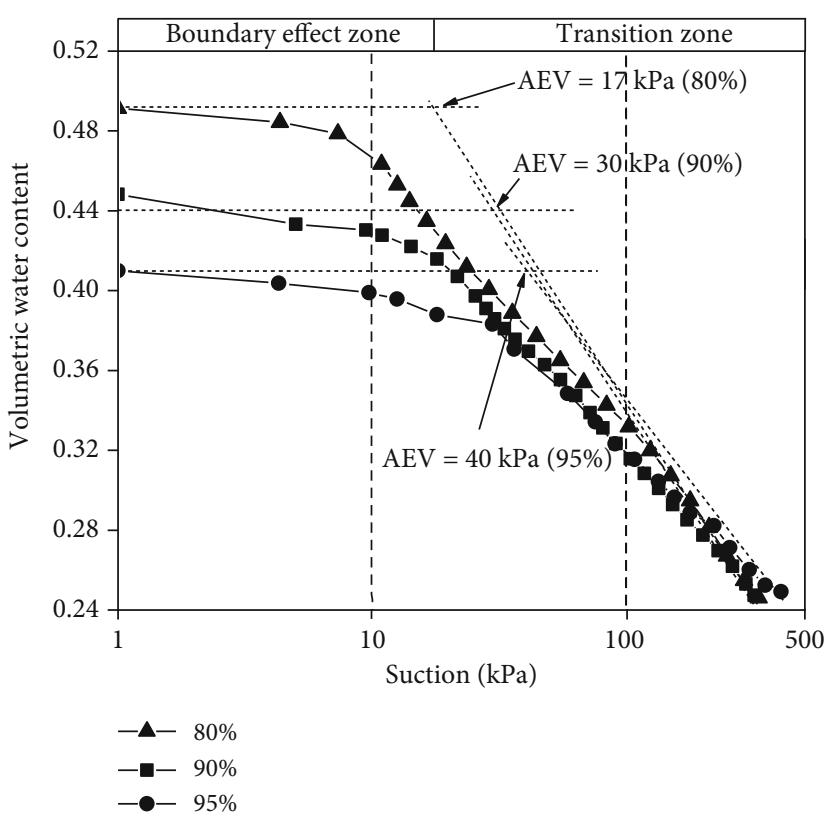

FIgURe 3: Effect of DOC on measured SWCCs of CDG.

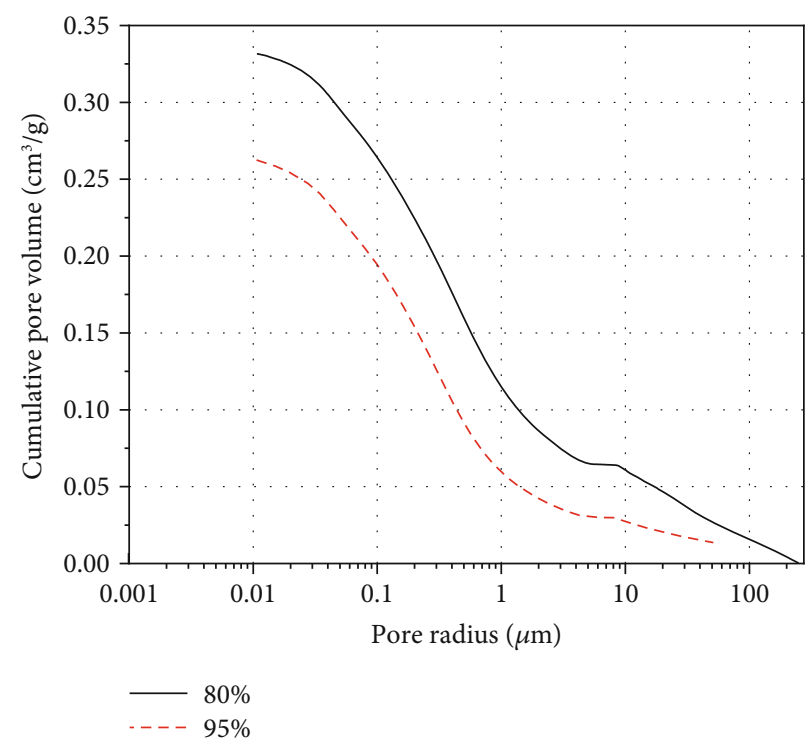

Figure 4: Cumulative pore volume curves of soil specimens at DOC of $80 \%$ and $95 \%$.

to a poor fitting near the AEV. As shown in Table 2, although the Gardner model showed a higher value of $R^{2}$ for fitting SWCCs of CDG at different values of DOC, it could not accurately obtain the AEV of the soil. The AEV predicted by the Gardner model (i.e., 1/a $a_{1}$ ) was about 4 times different from the value determined from experimental data. The parameters $n_{2}$ and $n_{3}$ indicate the desorption rate in the van Genuchten model and the Fredlund and Xing model, respectively. With the increase in DOC, the value of parameter $n_{2}$ in the van Genuchten model increased from 1.237 to 1.250 , whereas the value of parameter $n_{3}$ in the Fredlund and Xing model decreased from 0.503 to 0.456 . It seems that the effect of 


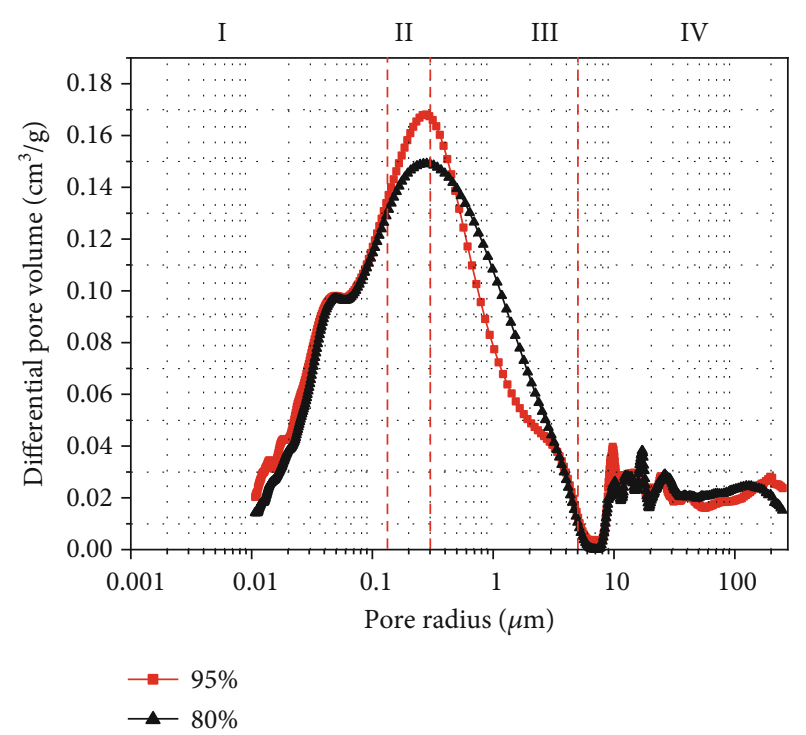

FIgURe 5: Pore size distribution of soil specimens at DOC of $80 \%$ and $95 \%$.

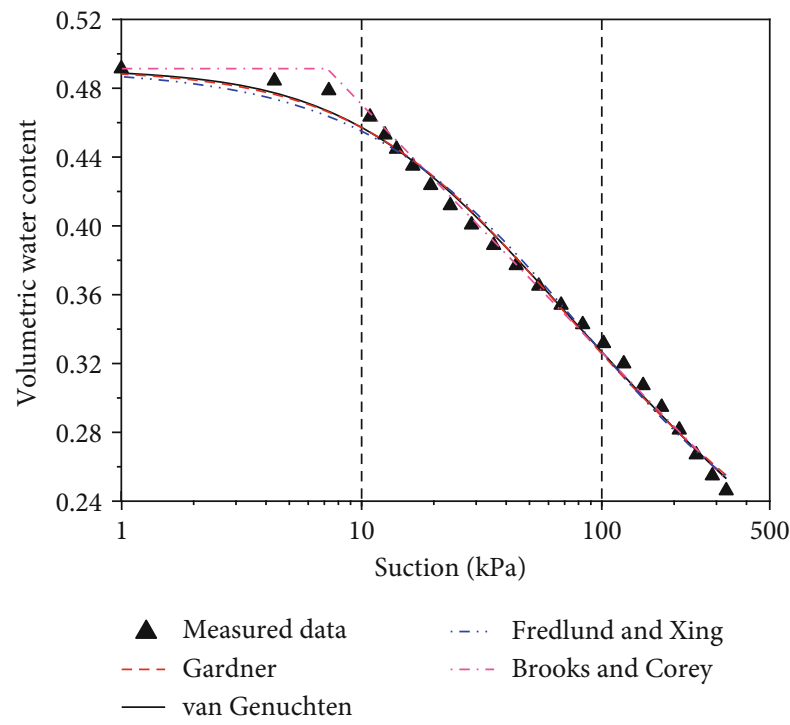

FIGURE 6: Fitting of SWCC at DOC of $80 \%$ using different models.

DOC on the desorption rate of SWCC was better described by the Fredlund and Xing model, which is more consistent with the experimental observations. Therefore, the Fredlund and Xing model is recommended as the best-fit model for SWCCs of CDG at various values of DOC.

3.2. Measured UPF. Figure 9 shows the UPFs of CDG at different values of DOC. The measured permeability coefficients of CDG at three values of DOC show a nearly linear decrease with soil suction in the double logarithmic coordinate system, when the suction range exceeds the AEV. Furthermore, the difference among the unsaturated permeability of CDG at different values of DOC became smaller as suction increased. This is because when the suction

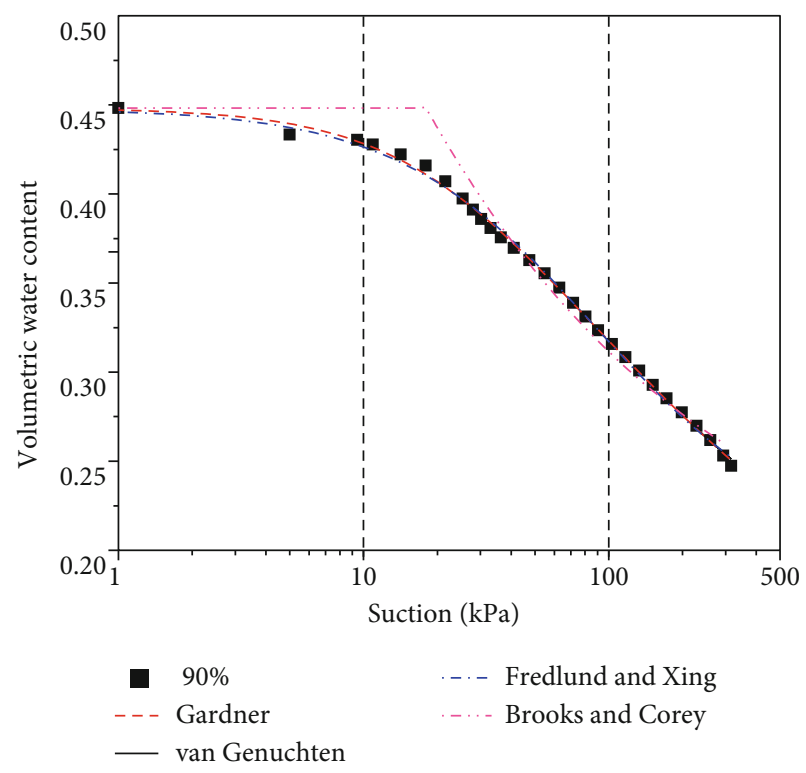

FIGURE 7: Fitting of SWCC at DOC of $90 \%$ using different models.

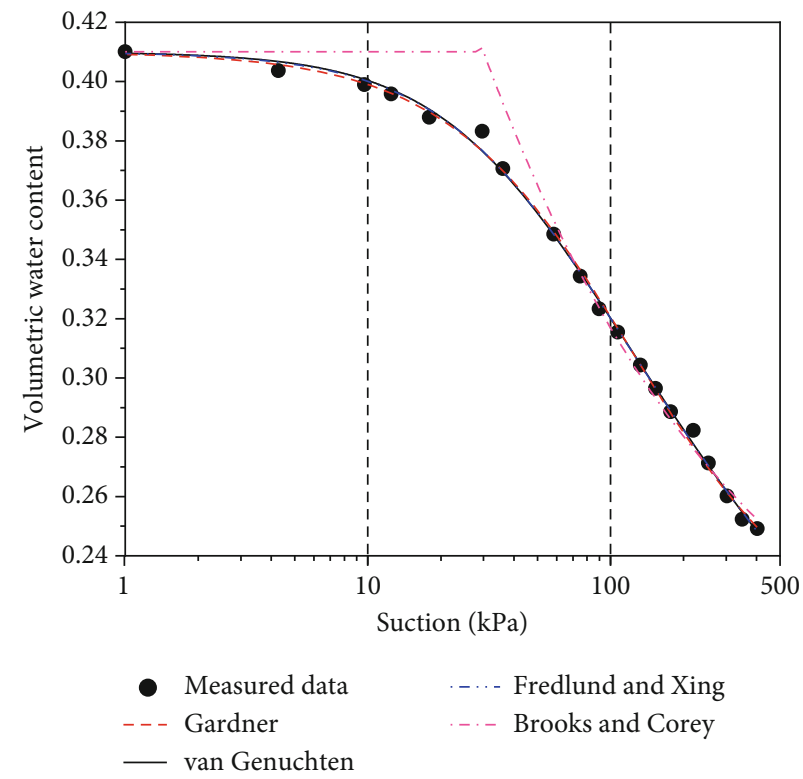

FIGURE 8: Fitting of SWCC at DOC of $95 \%$ using different models.

was high, the macropores of the soil specimen were filled with air and hence the water retention capacity of the soil specimen was mainly controlled by micropores. Lloret et al. [27] and Sivakumar et al. [28] investigated the effect of compaction on the pores of soil, and found that increasing compaction effort mainly reduced the volume of macropores, but had negligible effect on the volume of micropores. As shown in Figure 5, the DOC mainly changed the volume of pores with radii larger than $0.14 \mu \mathrm{m}$ in the soil, while the volume of pores with radii smaller than $0.14 \mu \mathrm{m}$ (zone I) remained unaffected by DOC. Given that the volume of micropores in CDG at different values of DOC was similar, the difference in UPFs in the high suction range should be small. 
TABLE 2: Fitting parameters of SWCCs.

\begin{tabular}{|c|c|c|c|c|c|c|c|c|c|c|c|c|c|}
\hline \multirow[t]{2}{*}{ Soil } & \multirow[t]{2}{*}{ DOC } & \multirow{2}{*}{$\begin{array}{l}\text { Initial dry density, } \\
\qquad \rho_{\mathrm{d}}\left(\mathrm{g} / \mathrm{cm}^{3}\right)\end{array}$} & \multirow{2}{*}{$\begin{array}{l}\text { Saturated volumetric } \\
\text { water content, } \theta_{\mathrm{s}}\left(\mathrm{cm}^{3} / \mathrm{cm}^{3}\right)\end{array}$} & \multicolumn{2}{|c|}{$\begin{array}{l}\text { Gardner } \\
\text { (1958) }\end{array}$} & \multicolumn{3}{|c|}{$\begin{array}{c}\text { van Genuchten } \\
(1980)\end{array}$} & \multicolumn{3}{|c|}{$\begin{array}{l}\text { Fredlund and } \\
\text { Xing (1994) }\end{array}$} & \multicolumn{2}{|c|}{$\begin{array}{l}\text { Brooks and } \\
\text { Corey (1965) }\end{array}$} \\
\hline & & & & $1 / a_{1}$ & $n_{1}$ & $a_{2}$ & $n_{2}$ & $m_{1}$ & $a_{3}$ & $n_{3}$ & $m_{2}$ & $\lambda$ & $\psi_{b}(\mathrm{kPa})$ \\
\hline \multirow{3}{*}{$\mathrm{CDG}$} & $80 \%$ & 1.328 & 0.49 & 50.5 & 0.687 & 19.6 & 1.237 & 0.192 & 22.6 & 0.503 & 1.5 & 0.162 & 7.2 \\
\hline & $90 \%$ & 1.494 & 0.45 & 74.6 & 0.726 & 29.3 & 1.247 & 0.198 & 29.3 & 0.487 & 1.25 & 0.208 & 18 \\
\hline & $95 \%$ & 1.577 & 0.41 & 117.6 & 0.739 & 51.59 & 1.250 & 0.200 & 40.3 & 0.456 & 1.1 & 0.204 & 30.2 \\
\hline
\end{tabular}

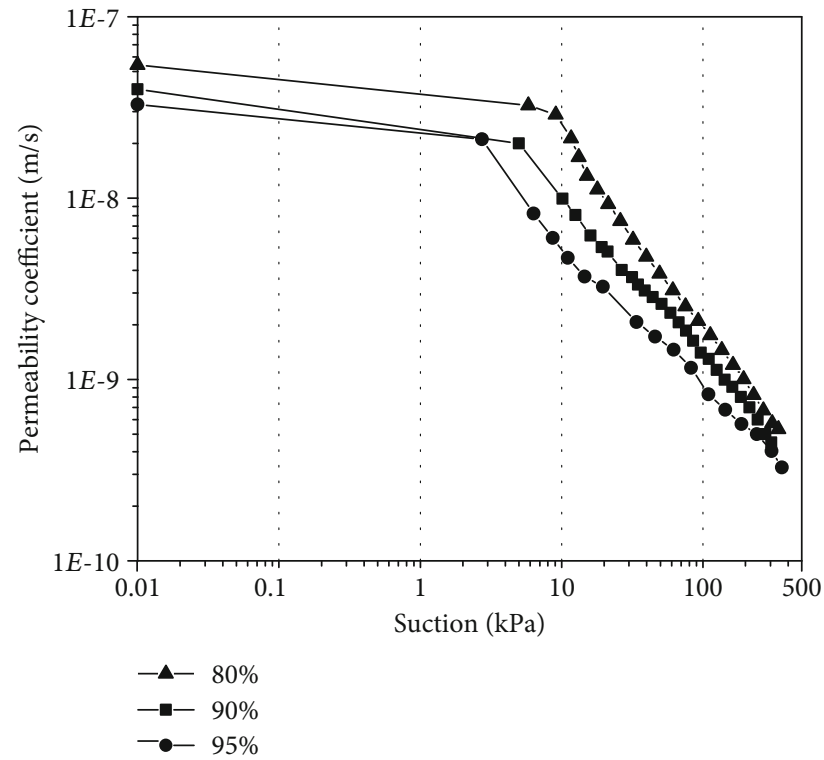

Figure 9: Effect of DOC on measured UPFs of CDG.

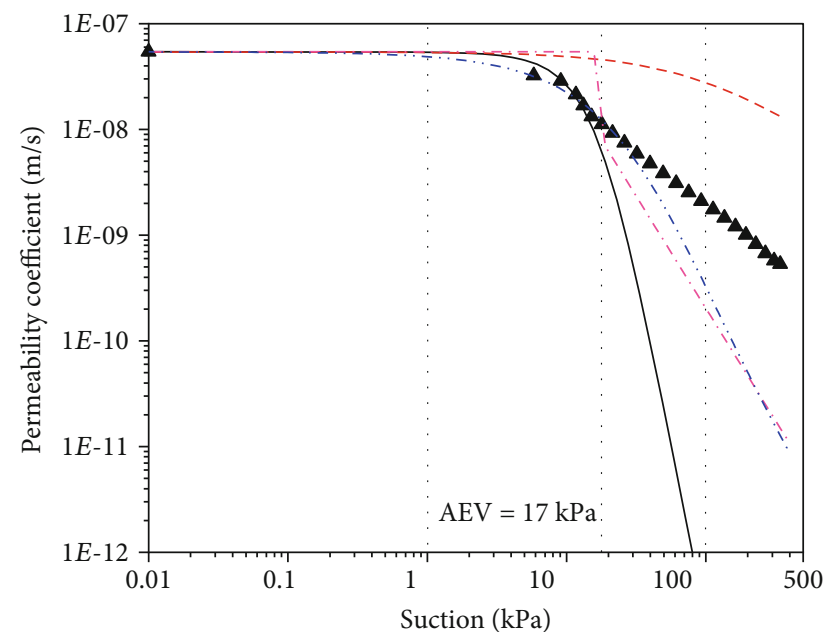
- Measured data
- - Gardner
..... Fredlund and Xing
_ - van Genuchten

Figure 10: Prediction of UPFs at DOC of $80 \%$ using different models.

3.3. Prediction of UPF. In Section 3.2, four SWCC models were used to fit the SWCCs of CDG at various values of DOC. Subsequently, four UPF predictions corresponding to these four SWCC models were made.

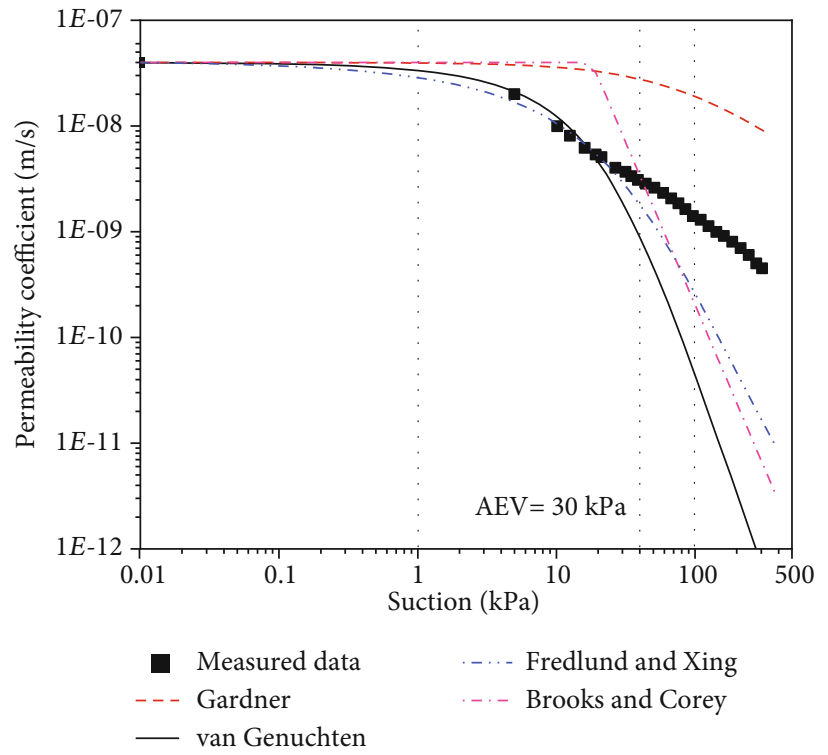

FIgURE 11: Prediction of UPFs at DOC of $90 \%$ using different models.

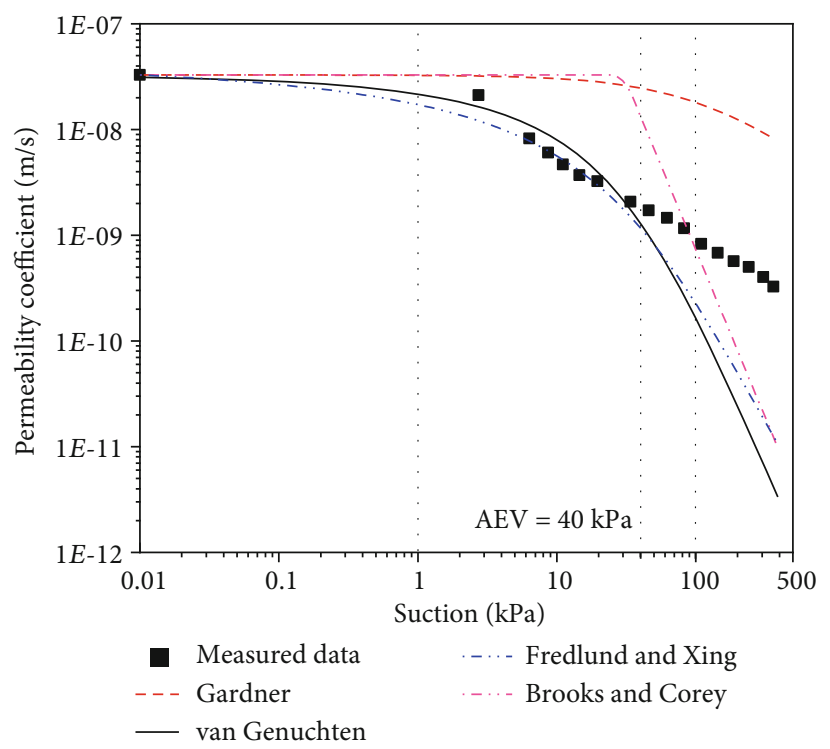

FIgURE 12: Prediction of UPFs at DOC of 95\% using different models.

Figures 10-12 show the predicted permeability curves for CDG at different values of DOC. For the specimen at DOC of $80 \%$, except for the Gardner model, the UPF predicted by the rest of the models agreed reasonably well for suction below 
TABLE 3: Values of NRMSE for UPFs of CDG at different values of DOC.

\begin{tabular}{lccc}
\hline Model & DOC $=80 \%$ & DOC $=90 \%$ & DOC $=95 \%$ \\
\hline Gardner & 2.33 & 2.15 & 2.23 \\
Brooks and Corey & 2.05 & 2.60 & 1.71 \\
van Genuchten & 8.72 & 3.13 & 1.73 \\
Fredlund and Xing & 1.69 & 1.85 & 1.40 \\
\hline
\end{tabular}

TABLE 4: Values of NRMSE for UPFs of CDG at different values of DOC in suction range of $\mathrm{AEV} \sim 500 \mathrm{kPa}$.

\begin{tabular}{lccc}
\hline Model & DOC $=80 \%$ & DOC $=90 \%$ & DOC $=95 \%$ \\
\hline Gardner & 3.67 & 4.81 & 5.46 \\
Brooks and Corey & 3.25 & 5.28 & 3.59 \\
van Genuchten & 14.1 & 6.99 & 4.76 \\
Fredlund and Xing & 2.73 & 4.12 & 3.86 \\
\hline
\end{tabular}

AEV. For the specimens at DOC of $90 \%$ and $95 \%$, the UPFs predicted by the Gardner model and Brooks and Corey model differed greatly from the measured data when the suction exceeded $1 \mathrm{kPa}$, but the UPFs predicted by the van Genuchten model and the Fredlund and Xing model were close to the measured data when the suction was smaller than AEV. However, as shown in Figures 10-12, the UPFs predicted by the four models show an obvious deviation from the measured ones at the suction range higher than AEV. To quantify the difference between the predicted and measured UPFs, the normalized root mean square error (NRMSE) was computed according to Equation (14) for all the predictions:

$$
\text { NRMSE }=\frac{\sqrt{\sum_{i=1}^{i=N}\left(\log \left(y_{i}\right)-\log \left(\widehat{y}_{i}\right)\right)^{2}}}{\log \left(y_{i \max }\right)-\log \left(y_{i \min }\right)},
$$

where $y_{i}$ is the measured value of UPF, $\hat{y}_{i}$ is the predicted value by a model, $N$ is the number of measurement data, $y_{i \min }$ is the minimum measurement value, and $y_{i \text { max }}$ is the maximum measurement value.

The NRMSE values of the four prediction models for UPFs at various values of DOC are listed in Table 3. The minimum value of NRMSE was achieved by the Fredlund and Xing model, which means this model provided the best prediction in the suction range of $0 \sim 500 \mathrm{kPa}$ among the four models.

To evaluate the difference between the predicted and measured UPFs particularly for suction greater than AEV, the NRMSE values in the suction range of AEV $500 \mathrm{kPa}$ are computed and summarized in Table 4 . The values of NRMSE of all models in the suction range of AEV $500 \mathrm{kPa}$ were much greater than those in the suction range of $0 \sim 500 \mathrm{kPa}$. The difference may be attributed to the fact that these prediction models assumed that soil has a rigid pore structure. Hence, the prediction models could not reflect the influence of soil deformation and pore structure change during the desaturation process $[9,29]$. Actually, for unsaturated soil, the permeability is significantly affected by the degree of saturation of the soil. Water flows through the pore spaces filled with water; therefore, the percentage of voids filled with water is an important factor [30]. Since the models used in this study were not able to consider the effect of volume contraction during the drying process, the proportion of voids filled with water predicted by the models were smaller than the actual percentage of water-filled pores, causing the value of permeability coefficient predicted by the models smaller than the measured one.

\section{Conclusions}

To investigate the influence of DOC on SWCCs and UPFs of a compacted CDG, a series of simplified evaporation tests and falling-head permeability tests were carried out on soil specimens at different values of DOC. Four models proposed by Gardner, Brooks and Corey, van Genuchten, and Fredlund and Xing [9-12] were used to predict the UPFs of CDG at different values of DOC. The measured UPFs were then compared with the predicted ones. The following conclusions were drawn:

(1) The influence of DOC on SWCCs and UPFs of CDG was of great significance within the suction of $100 \mathrm{kPa}$, whereas the influence became marginal when the suction exceeded $100 \mathrm{kPa}$. Moreover, the DOC mainly altered the volume of pores with radii larger than $0.14 \mu \mathrm{m}$, whereas its effect on pores with radii smaller than $0.14 \mu \mathrm{m}$ was negligible

(2) Based on the fitted results of SWCCs along the drying path, the Fredlund and Xing model was recommended as the best-fit model for the SWCCs of CDG at different values of DOC

(3) The comparison of measured UPFs with the predicted ones showed that reasonable predictions were obtained only when suction was less than AEV, and the Fredlund and Xing model provided the best estimation among the four models. It is suggested that better predictions of UPFs at suctions higher than AEV could be achieved by considering the suctioninduced volume contraction

\section{Data Availability}

Measurement data of the SWCCs and UPFs of CDG at different values of DOC were generated by the experimental work. The data used to support the findings of this study are available from the corresponding author upon request.

\section{Conflicts of Interest}

The authors declare that there is no conflict of interest regarding the publication of this paper.

\section{Acknowledgments}

The authors acknowledge the financial support from the Science, Technology, and Innovation Commission of Shenzhen 
Municipality (Grant No. JCYJ20170811160740635), the National Natural Science Foundation of China (Grant No. 51808171), the Guangdong Natural Science Foundation (Grant No. 2018A030310018), and the State Key Laboratory of Simulation and Regulation of Water Cycle in River Basin, China Institute of Water Resources and Hydropower Research (Grant No. IWHR-SKL-KF201811).

\section{References}

[1] R. Chen and C. W. W. Ng, "Impact of wetting-drying cycles on hydro-mechanical behavior of an unsaturated compacted clay," Applied Clay Science, vol. 86, no. 8, pp. 38-46, 2013.

[2] R. Chen, T. Xu, W. Lei, Y. Zhao, and J. Qiao, "Impact of multiple drying-wetting cycles on shear behaviour of an unsaturated compacted clay," Environmental Earth Sciences, vol. 77, no. 19, 2018.

[3] L.-s. Tang, B. Yan, Z.-s. Li, H.-t. Yu, and G.-w. Lin, "The experimental research on the soil-water characteristic curve of the granite residual soil," Hydrogeology \& Engineering Geology, vol. 35, no. 4, pp. 62-65, 2008.

[4] D. X. Chen and X. N. Gong, "Experiment and modeling of soilwater characteristic curve of unsaturated residual soil," Rock and Soil Mechanics, vol. 35, no. 7, pp. 1885-1891, 2014.

[5] J. H. Yin, "Influence of relative compaction on the hydraulic conductivity of completely decomposed granite in Hong Kong," Canadian Geotechnical Journal, vol. 46, no. 10, pp. 1229-1235, 2009.

[6] C. Gallage, J. Kodikara, and T. Uchimura, "Laboratory measurement of hydraulic conductivity functions of two unsaturated sandy soils during drying and wetting processes," Soils and Foundations, vol. 53, no. 3, pp. 417-430, 2013.

[7] U. Schindler and L. Müller, "Simplifying the evaporation method for quantifying soil hydraulic properties," Journal of Plant Nutrition and Soil Science, vol. 169, no. 5, pp. 623-629, 2006.

[8] A. Peters and W. Durner, "Simplified evaporation method for determining soil hydraulic properties," Journal of Hydrology, vol. 356, no. 1-2, pp. 147-162, 2008.

[9] D. G. Fredlund, A. Xing, and S. Huang, "Predicting the permeability function for unsaturated soils using the soil-water characteristic curve," Canadian Geotechnical Journal, vol. 31, no. 4, pp. 533-546, 1994.

[10] M. T. van Genuchten, "A closed-form equation for predicting the hydraulic conductivity of unsaturated soils," Soil Science Society of America Journal, vol. 44, no. 5, pp. 892-898, 1980.

[11] R. H. Brooks and A. T. Corey, "Hydraulic properties of porous media," Hydrology Paper, vol. 3, no. 1, pp. 352-366, 1964.

[12] W. R. Gardner, "Calculation of capillary conductivity from pressure plate outflow data," Soil Science Society of America Journal, vol. 20, no. 3, pp. 317-320, 1956.

[13] A. Rahimi, H. Rahardjo, and E. C. Leong, "Effect of range of soil-water characteristic curve measurements on estimation of permeability function," Engineering Geology, vol. 185, pp. 96-104, 2015.

[14] C. W. W. Ng, H. W. Liu, and S. Feng, "Analytical solutions for calculating pore-water pressure in an infinite unsaturated slope with different root architectures," Canadian Geotechnical Journal, vol. 52, no. 12, pp. 1981-1992, 2015.

[15] H. W. Liu, S. Feng, and C. W. W. Ng, "Analytical analysis of hydraulic effect of vegetation on shallow slope stability with different root architectures," Computers and Geotechnics, vol. 80, pp. 115-120, 2016.

[16] GB/T 50123-1999, The Standard Soil Test Methods, China Planning Press, Beijing, China, 1999.

[17] Y. X. Wang, P. P. Guo, W. X. Ren et al., "Laboratory investigation on strength characteristics of expansive soil treated with jute fiber reinforcement," International Journal of Geomechanics, vol. 17, no. 11, article 04017101, 2017.

[18] ASTM D5084, Standard Test Methods for Measurement of Hydraulic Conductivity of Saturated Porous Materials Using a Flexible Wall Permeameter, ASTM International, West Conshohocken, 2010.

[19] R. Chen, J. W. Huang, Z. K. Chen, Y. Xu, J. Liu, and Y. H. Ge, "Effect of root density of wheat and okra on hydraulic properties of an unsaturated compacted loam," European Journal of Soil Science, vol. 70, no. 3, pp. 493-506, 2019.

[20] R. Chen, J. Liu, J. H. Li, and C. W. W. Ng, “An integrated highcapacity tensiometer for measuring water retention curves continuously," Soil Science Society of America Journal, vol. 79, no. 3, pp. 943-947, 2015.

[21] D. G. Fredlund and H. Rahardjo, Soil Mechanics for Unsaturated Soils, Wiley, 1993.

[22] D. Penumadu and J. Dean, "Compressibility effect in evaluating the pore-size distribution of kaolin clay using mercury intrusion porosimetry," Canadian Geotechnical Journal, vol. 37, no. 2, pp. 393-405, 2000.

[23] T. Y. Zhao and J. F. Wang, "Soil-water characteristic curve for unsaturated loess soil considering density and wetting-drying cycle effects," Journal of Central South University (Science and Technology), vol. 43, no. 6, pp. 2445-2453, 2012.

[24] D. L. Wang, M. T. Luan, and Q. Yang, "Experimental study of soil-water characteristic curve of remolded unsaturated clay," Rock and Soil Mechanics, vol. 30, no. 3, pp. 751-756, 2009.

[25] R. Chen, T. Xu, Y. R. Zhao, G. Deng, J. Qiao, and S. da Zhou, "Effects of net normal stress on hydro-mechanical behaviour of a kaolinite clay soil under different suction paths," Environmental Earth Sciences, vol. 78, no. 24, 2019.

[26] Q. Cheng, C. W. W. Ng, C. Zhou, and C. S. Tang, “A new water retention model that considers pore non-uniformity and evolution of pore size distribution," Bulletin of Engineering Geology and the Environment, vol. 78, no. 7, pp. 5055-5065, 2019.

[27] A. Lloret, M. V. Villar, M. Sánchez, A. Gens, X. Pintado, and E. E. Alonso, "Mechanical behaviour of heavily compacted bentonite under high suction changes," Géotechnique, vol. 53, no. 1, pp. 27-40, 2003.

[28] V. Sivakumar, W. C. Tan, E. J. Murray, and J. D. McKinley, "Wetting, drying and compression characteristics of compacted clay," Géotechnique, vol. 56, no. 1, pp. 57-62, 2006.

[29] N. T. Burdine, "Relative permeability calculations from pore size distribution data," Journal of Petroleum Technology, vol. 5, no. 3, pp. 71-78, 1953.

[30] R. Chen, Y. Ge, Z. Chen, J. Liu, Y. Zhao, and Z. Li, “Analytical solution for one-dimensional contaminant diffusion through unsaturated soils beneath geomembrane," Journal of Hydrology, vol. 568, pp. 260-274, 2019. 